\title{
Uso do diluente água de coco em pó (ACP-103®) na conservação prolongada do sêmen do varrão: avaliação in vitro e in vivo
}

\author{
[Use of powder coconut water as extender (ACP-103®) for boar semen longer preservation: \\ in vitro and in vivo evaluations] \\ R. Toniolli ${ }^{1}$, G.H. Toniollo ${ }^{2}$, P.H. Franceschini ${ }^{2}$, F.M.A.C. Morato $^{2}$ \\ ${ }^{1}$ Faculdade de Veterinária - UECE \\ Av. Paranjana, 1700 \\ 60740-000 - Fortaleza, CE \\ ${ }^{2}$ Faculdade de Ciências Agrárias e Veterinárias - UNESP - Jaboticabal, SP
}

\begin{abstract}
RESUMO
O sêmen de oito reprodutores foi coletado e de cada ejaculado separou-se um total de $1,75 \times 10^{9}$ sptz, com concentração de $35 \times 10^{6} \mathrm{sptz} / \mathrm{mL}$. Usou-se o Beltsville Thawing Solution (BTS) como controle para testar o diluente água de coco em pó (ACP). O dia de coleta foi o dia zero (D0), sendo o sêmen conservado durante cinco dias, com análises diárias no D0 e nos quatro dias seguintes (D1, D2, D3 e D4). A avaliação da qualidade espermática baseou-se nos resultados do vigor espermático, da porcentagem de células móveis, da morfologia espermática, da integridade da membrana plasmática e dos resultados de fertilidade. As avaliações do vigor espermático $(4,1)$ e da porcentagem de espermatozoides móveis $(91 \%)$ ficaram acima dos parâmetros mínimos exigidos (3,0 e 70\%) para sua utilização em programas de inseminação artificial, pois não houve influência sobre as variáveis analisadas pelo protocolo experimental. $\mathrm{O}$ resultado médio da resistência osmótica foi de $71,3 \%$ de espermatozoides com cauda enrolada. Não houve diferenças entre os dois diluentes testados para a característica células com acrossoma intacto $(\mathrm{BTS}=67,1 \%$; ACP $=71,2 \%$ ). O sêmen diluído em ACP apresentou maior número de células vivas $(77,7 \%)$ com membrana plasmática íntegra $(74,2 \%)$ após a conservação. A escolha do diluente ACP é aconselhável para uso de rotina em laboratórios que trabalhem com conservação de sêmen suíno. Apesar dos bons resultados in vitro obtidos com o diluente ACP, o BTS apresentou os melhores resultados de fertilidade, $86,7 \%$ e $96,7 \%$, respectivamente.
\end{abstract}

Palavras-chave: suíno, sêmen, água de coco, conservação, morfologia, fertilidade

\begin{abstract}
The semen of eight boars was collected and a total of $1.75 \times 10^{9}$ spermatozoa were separated from each ejaculate, obtaining a concentration of $35 \times 10^{6} \mathrm{sptz} / \mathrm{mL}$. The Beltsville Thawing Solution (BTS) was used as control, being tested the powder coconut water as extender $(P C W)$. The day of collection was considered day zero (DO), and the semen was conserved for five days, with analyses on DO and on four subsequent days (DI, D2, D3, and D4). The evaluation of spermatic quality was based on the results of spermatozoa vigour, cells motility, spermatic morphology, plasmatic membrane integrity, and fertility. The evaluations of the in natura semen presented mean values of spermatozoa vigour (4.1) and mobile spermatozoids percentage (91\%) above the demanded minimum parameters (3.0 and 70\%) for its use in artificial insemination programs without influencing on the analyzed variables. The mean results of the osmotic resistance were excellent, with $71.3 \%$ of spermatozoids with coiled tail. There were no differences between the two extenders tested for the characteristic cells with intact acrossome $(B T S=67.1 \% ; P C W=71.2 \%)$. The semen diluted in PCW extender presented a higher number of alive cells (77.7\%) with a complete plasmatic membrane (74.2\%) after conservation period. The choice of PCW extender is advisable for the routine use in laboratories that work with conservation of swine semen. In spite of the good results in vitro with the PCW extender, the BTS presented the best fertility results, $86.7 \%$ and $96.7 \%$, respectively.
\end{abstract}

Keywords: swine, semen, cocconut water, conservation, morphology, fertility

Recebido em 24 de setembro de 2009

Aceito em 10 de agosto de 2010

E-mail: toniolli@ roadnet.com.br 


\section{INTRODUÇÃO}

Vários são os testes laboratoriais utilizados para a avaliação de ejaculados de reprodutores suínos (Slaweta et al., 1981), entretanto, apesar dessa grande variedade, ainda não se tem uma definição precisa de avaliação de um sêmen fértil (Yavetz et al., 1995). Uma vez que a função acrossômica desempenha importante papel nos processos de fertilização, o estudo dessa característica torna-se indispensável na avaliação de um ejaculado (Toniolli et al., 1999).

Sabe-se que a longevidade espermática do sêmen do varrão mantém-se satisfatória durante 72 horas, à temperatura de $16^{\circ} \mathrm{C}$, em diferentes diluentes até então utilizados (Figueirôa et al., 2001), período este insuficiente para o bom aproveitamento de reprodutores. Dessa forma, a avaliação de novos meios de diluição é importante para se obter uma adequada conservação da célula espermática. A procura por novos diluentes para o sêmen do varrão levou pesquisadores a estudarem a água de coco em pó (ACP) como uma alternativa viável na substituição dos tradicionais diluentes comerciais existentes no mercado (Salgueiro et al., 2007).

A fertilidade é uma característica que pode variar de acordo com o indivíduo; desta forma, vários métodos foram utilizados com a finalidade de avaliar os ejaculados dos reprodutores (Arruda et al., 2007) visando a sua inclusão em programas de inseminação artificial. Existem diferenças de desempenho reprodutivo entre criações que parecem estar associadas à duração do período de estocagem do sêmen (Haugan et al., 2005). O efeito desse período sobre a qualidade espermática tem sido investigado, e a tolerância a esta conservação, sem decréscimo da qualidade, depende, dentre outros fatores, da escolha do diluente (Levis, 2000).

O presente trabalho teve como objetivo testar a água de coco em pó na conservação prolongada do sêmen do varrão sob a forma refrigerada, por meio de análises in vitro e resultados de fertilidade de fêmeas inseminadas.

\section{MATERIAL E MÉTODOS}

O sêmen de oito reprodutores, em sistema rotineiro, foi coletado durante 12 semanas, por meio da técnica da mão enluvada em recipiente coberto por gaze e protegido por copo térmico, sendo utilizado o ejaculado total após a separação da parte gelatinosa. A qualidade do ejaculado foi avaliada pela concentração $\left(\mathrm{x} 10^{6} \mathrm{sptz} / \mathrm{mL}\right)$, pelo volume $(\mathrm{mL})$, pelo total de espermatozoides (x10 $\left.10^{9} \mathrm{sptz}\right)$, vigor espermático (0 a 5) e pela porcentagem de células móveis (\%).

Foi separado de cada ejaculado um total de $1,75 \times 109$ sptz, repartidos entre dois tratamentos (concentração de $35 \times 10^{6} \mathrm{sptz} / \mathrm{mL}$ ), com um volume final por tratamento $(25 \mathrm{~mL}=$ sêmen + diluente) repartido em cinco tubos de ensaio por tratamento $\left(5 \mathrm{~mL}=175 \times 10^{6} \mathrm{sptz} /\right.$ tubo $)$. Cada tubo referente a um dia de análise foi conservado entre 15 a $17^{\circ} \mathrm{C}$ durante cinco dias. $\mathrm{O}$ dia da colheita foi considerado dia zero (D0), e o sêmen foi conservado até quatro dias após (D4), com análises diárias no D0, D1, D2, D3 e D4. O Beltsville Thawing Solution (BTS) foi $\mathrm{o}$ tratamento controle, e o diluente água de coco em pó (ACP-103 ${ }^{\circledR}$ ), oriundo da desidratação da água de coco in natura, pela técnica do spray dry (Salgueiro et al., 2002), foi o tratamento testado, sendo reconstituído com água destilada nas seguintes proporções: $24 \mathrm{~g}$ de ACP-103 $+100 \mathrm{~mL}$ de água destilada + sulfato de gentamicina a $80 \mathrm{mg} / 100 \mathrm{~mL}$. A cada dia de análise, foram retirados os tubos equivalentes a cada ejaculado/tratamento, incubados a $37^{\circ} \mathrm{C}$ por 10 minutos.

Para a avaliação da qualidade espermática, foi analisado o vigor espermático (0 a 5; Toniolli, 1996) e a porcentagem de células móveis (\%), colocando-se uma gota de sêmen de $15 \mu \mathrm{L}$ entre lâmina e lamínula e com leitura com um aumento de 200 vezes. O sêmen diluído e conservado entre 15 a $17^{\circ} \mathrm{C}$ foi reaquecido a $37^{\circ} \mathrm{C}$, com leituras feitas após 10 minutos de incubação.

As amostras para morfologia foram processadas no D0, após coleta e diluição (Exame 1) e no D4, antes da incubação (Exame 2), considerando-se a morfologia do acrossoma e a vitalidade (\% de células vivas). Foram feitos esfregaços de sêmen corados, contando-se 200 células/esfregaço em microscopia óptica com lente de imersão (aumento de 1000x). A solução corante foi formada por: azul de bromo-fenol $=0,1 \mathrm{~g}$; citrato de sódio $=0,4 \mathrm{~g}$; água destilada $=10 \mathrm{~mL}$. Juntouse uma gota de sêmen com outra de corante sendo homogeneizada em seguida. Após 30 segundos, procedeu-se ao esfregaço, sendo 
secado à temperatura ambiente. Para análises, os espermatozoides foram classificados em três categorias: 1) espermatozoides vivos com acrossoma intacto; 2) espermatozoides vivos com acrossoma danificado; 3) espermatozoides mortos.

A avaliação da integridade de membrana foi feita pela coloração fluorescente em microscopia óptica de campo escuro, com uma mistura de corantes biológicos. Para o meio de coloração, adicionaram-se $20 \mu \mathrm{L}$ da solução de formaldeído, $20 \mu \mathrm{L}$ da solução de diacetato de carboxifluoresceína (DIC) e $10 \mu \mathrm{L}$ da solução de iodeto de propídio (IP) para cada mililitro $(\mathrm{mL})$ da solução salina estoque. Um total de $10 \mu \mathrm{L}$ da suspensão de sêmen, contendo $10 \times 10^{6} \mathrm{sptz} / \mathrm{mL}$, foi diluído em $40 \mu \mathrm{L}$ de meio de coloração. Uma alíquota de $5 \mu \mathrm{L}$ da suspensão foi colocada entre lâmina e lamínula sob aumento de 1000x com iluminação epifluorescente, com filtros de fluoresceína padrão (luz azul) e rodamina padrão (cor verde), alternadamente para os corantes DIC e IP, respectivamente. Foram contadas 200 células por alíquota/tratamento. Os espermatozoides foram classificados em três categorias: 1) membrana íntegra (I): toda a célula que acumula a DIC (fluorescência verde) ao longo de sua cabeça e flagelo, sem acúmulo da IP (fluorescência vermelha); 2) membrana parcialmente danificada (II): acúmulo de DIC na peça intermediária e/ou região acrossomal, enquanto a cabeça e a cauda se coram com IP; 3) membrana danificada (III): acúmulo apenas de IP ao longo da célula.

Os doadores de sêmen utilizados para a inseminação artificial encontravam-se em coleta regular e apresentavam boa saúde. Foram utilizadas fêmeas adultas na formação dos lotes, ou marrãs, com distribuição equilibrada entre os diferentes tratamentos. As inseminações foram realizadas na Granja Suinícola Estiva, no município de Jaboticabal-SP, com os lotes de inseminação formados com o sêmen diluído nos diluentes BTS e ACP, sendo inseminadas 30 fêmeas por tratamento. Cada fêmea recebeu três inseminações por estro com um total de $4 \times 10^{9}$ sptz cada, e o intervalo entre inseminações (IA) foi de 12 horas, com os seguintes tempos contados após a fêmea apresentar reação positiva ao reprodutor e tratador: 1 ) marrãs: primeira IA = zero hora; segunda IA = 12 horas; terceira IA =
24 horas; 2) porcas: primeira IA $=24$ horas; segunda IA $=36$ horas; terceira IA $=48$ horas. $\mathrm{Na}$ avaliação dos resultados de fertilidade, usaram-se as seguintes características: 1) total de fêmeas inseminadas; 2) número total de leitões/barrigada; 3) porcentagem de porcas paridas; 4) média de leitões nascidos vivos/porca; 5) proporção macho x fêmea.

O delineamento experimental utilizado foi o de blocos ao acaso, usando-se análise de variância e aplicando-se os testes Mann Whitney, para a comparação entre grupos, e qui-quadrado, corrigido para os resultados expressos em porcentagem. A análise das diferenças entre médias foi feita por variância multifatorial usando-se o General Linear Models do SAS/1988, com significância de 5\% $(\mathrm{P}<0,05)$.

\section{RESULTADOS E DISCUSSÃO}

Após a diluição do sêmen, o vigor espermático apresentou valores médios mais altos $(\mathrm{P}<0,05)$ durante quase todo o período de conservação (D1, D2 e D3), nos ejaculados conservados no diluente ACP. Houve equivalência aos obtidos com o BTS apenas no dia de coleta do sêmen (D0) e no último dia de conservação (D4) $(\mathrm{P}>0,05)$, indicando que o ACP apresentou melhor capacidade de manutenção dessa característica durante o período de conservação do sêmen. Este novo diluente tem-se mostrado eficiente em diferentes processos biotecnológicos de espécies animais bem como no homem (Nunes e Salgueiro, 1999; Costa et al., 2002), o que abre uma nova perspectiva para o seu uso. A queda normal dos valores do vigor espermático, que acontece durante o período de conservação do sêmen (de D0 a D4), foi menor nos espermatozoides conservados no ACP $(4,5 \%=$ 2,2 a 2,1) em relação aos no BTS $(13,6 \%=2,2$ a $1,9)$. Esta melhor condição de conservação pode ser constatada pelos valores mais altos durante todo o período de conservação do sêmen nos ejaculados conservados no $\mathrm{ACP}(\mathrm{D} 1=2,4$; D2 = 2,3; D3 = 2,4 e D4 = 2,1) em relação aos diluídos no BTS $(\mathrm{D} 1=2,1 ; \mathrm{D} 2=2,0 ; \mathrm{D} 3=2,1$ e D4 = 1,9), uma vez que, nos dois tratamentos, o sêmen partiu de um mesmo valor $(2,2)$ após sua diluição (Fig. 1).

Para a característica porcentagem de espermatozoides móveis, os resultados foram ainda mais favoráveis quando se utilizou o ACP 
como meio de diluição do sêmen, com diferenças significativas $(\mathrm{P}<0,05)$ durante todo o período de conservação, em relação ao BTS, exceto no D2. A queda dos valores entre o primeiro (D0) e o último dia (D4) de conservação do sêmen foi ligeiramente maior com o uso do ACP $(7,5 \%=$ 60 a 45) em relação ao do BTS $(6,7 \%=48$ a 32). Apesar disso, os valores médios obtidos no diluente ACP estiveram sempre acima dos obtidos com o BTS, durante todo o período de conservação (Fig. 2).
A conservação do sêmen sob a forma líquida a $15^{\circ} \mathrm{C}$ é, ainda na atualidade, o método mais largamente utilizado para o ejaculado do varrão. Apesar do limite de três dias e de resultados instáveis e insuficientes obtidos por outros pesquisadores (Paquignon et al., 1982; Weitze, 1995), a utilização de novos diluentes tem permitido um aumento desse prazo, com a obtenção de uma boa qualidade espermática ao final do período de conservação (Uchoa et al., 2007) e a quebra desse limite de utilização do ejaculado do varrão (Toniolli, 1996).

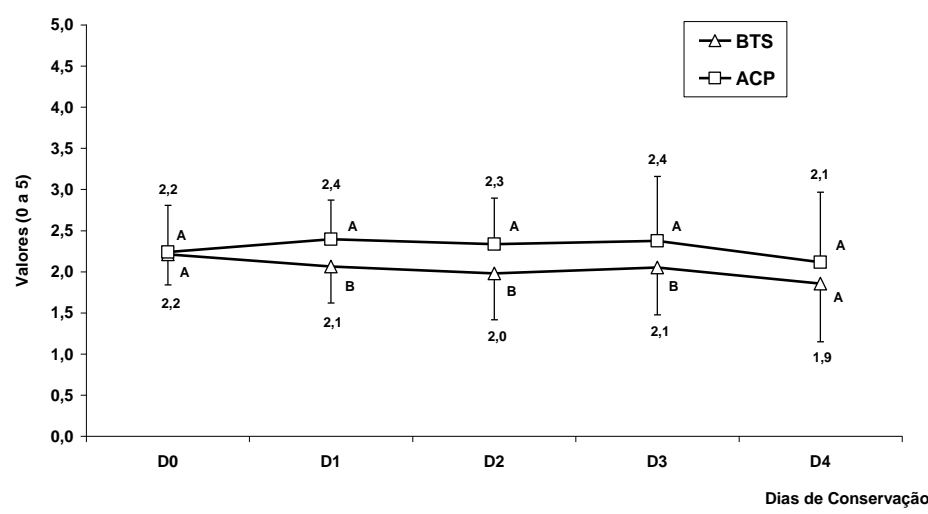

Letras diferentes dentro de mesmo dia de conservação indicam diferenças significativas $(\mathrm{P}<0,05)$.

Figura 1. Valores médios do vigor espermático do sêmen suíno, diluído em BTS e água de coco em pó (ACP), conservado entre 15 a $17^{\circ} \mathrm{C}$ durante cinco dias, e analisado após 10 minutos de incubação a $37^{\circ} \mathrm{C}$.

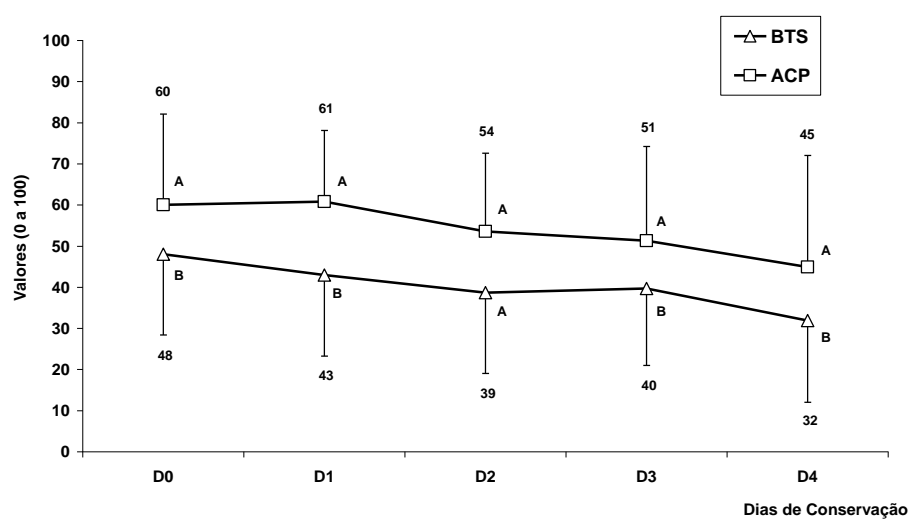

Letras diferentes dentro de mesmo dia de conservação indicam diferenças significativas $(\mathrm{P}<0,05)$.

Figura 2. Valores médios da porcentagem de espermatozoides móveis do sêmen suíno, diluído em BTS e água de coco em pó (ACP), conservado entre 15 a $17^{\circ} \mathrm{C}$ durante cinco dias, e analisado após 10 minutos de incubação a $37^{\circ} \mathrm{C}$. 
Quanto à morfologia espermática, no D0, houve queda $(\mathrm{P}<0,05)$ na porcentagem de células com acrossoma intacto no sêmen diluído (BTS = $67,1 \%$; ACP $=71,2 \%$ ) em relação ao sêmen in natura $(79,6 \%)$, e não houve diferenças $(\mathrm{P}>0,05)$ entre os valores dos dois diluentes testados. Estes resultados diferiram dos obtidos por Toniolli et al. (1999), em que o BTS resultou em menor número de células com acrossoma intacto, mas com o uso do ácido 3-indol acético, princípio ativo derivado da água de coco em concentrações maiores do que as encontradas no ACP. Dentro da característica acrossoma danificado, as diferenças entre os tratamentos (sêmen puro = $8,1 \%$; diluído em BTS $=16,2 \%$ e $\mathrm{ACP}=12,5 \%$ ) foram todas significativas $(\mathrm{P}<0,05)$, abrindo novas perspectivas com a utilização do ACP na conservação do sêmen do varrão. $\mathrm{Na}$ característica células mortas, não houve diferenças significativas entre os tratamentos (sêmen puro $=13,0 \%$; BTS $=16,7 \%$ e $\mathrm{ACP}=$ $16,3 \%)(\mathrm{P}>0,05)$ (Fig. 3).
Após o período de conservação do sêmen (D4), verificou-se que o diluente ACP proporcionou maior proteção e melhor meio aos espermatozoides, traduzidos por maior número de células vivas com acrossoma íntegro $(65,0 \%)$ em relação ao BTS $(40,1 \%)(\mathrm{P}<0,05)$. A ação das temperaturas mais baixas sobre a característica estudada pode ser vista neste trabalho da mesma forma que a citada por outros autores (Ruvalcaba e Conde Martinez, 2005; Lima et al., 2007).

Em relação à porcentagem de espermatozoides mortos, os melhores resultados foram encontrados também com o sêmen diluído no $\mathrm{ACP}$, com menor número de células mortas $(22,3 \%)$ em relação ao BTS $(41,5 \%)(\mathrm{P}<0,05)$. $\mathrm{Na}$ característica espermatozoide vivo com acrossoma danificado, não houve diferenças significativas entre os tratamentos $(\mathrm{P}>0,05)$ (Fig. 3).

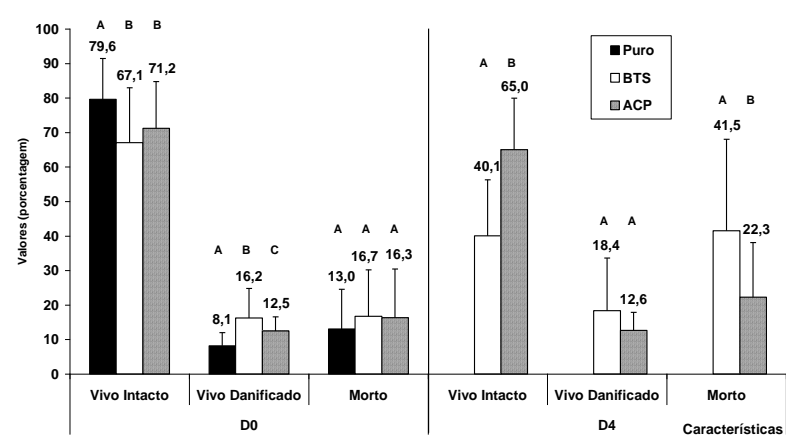

Letras diferentes entre tratamentos, dentro da mesma característica, indicam diferenças significativas $(\mathrm{P}<0,05)$.

Figura 3. Morfologia do acrossoma e da vitalidade espermática do sêmen suíno diluído em BTS e água de coco em pó (ACP), no dia da coleta (D0) e no último dia de conservação (D4), após 10 minutos de incubação a $37^{\circ} \mathrm{C}$.

Quanto ao sêmen no dia da coleta (D0) após diluição, houve queda $(\mathrm{P}<0,05)$ na porcentagem de células com membrana intacta (BTS $=49,1 \%$; $\mathrm{ACP}=68,4 \%$ ) em relação ao sêmen in natura $(78,0 \%)$. Entre tratamentos (BTS e ACP), as diferenças também foram significativas $(\mathrm{P}<0,05)$, mostrando-se o ACP mais eficiente em preservar a membrana espermática. Dentro da característica membrana danificada, as diferenças entre tratamentos foram significativas $(\mathrm{P}<0,05)$, tendo o diluente BTS o pior resultado (dano parcial $=36,0 \%$; dano total $=14,5 \%)$ (Fig. 4). Após o período de conservação do sêmen (D4), verificou-se que o ACP proporcionou, mais uma vez, as melhores condições de proteção aos espermatozoides $(\mathrm{P}<0,05)$, com maior número de células com membrana íntegra $(74,2 \%)$ em relação ao BTS $(39,0 \%)$. A mesma tendência foi evidenciada nas características dano parcial e total $(\mathrm{P}<0,05)$, com menor número de células com membrana danificada no ACP $(18,9 \%$ e $6,8 \%$, 
respectivamente) em relação ao $\mathrm{BTS}(37,1 \%$ e $23,8 \%$, respectivamente) (Fig. 4). Apesar de a incubação e de temperaturas mais baixas promoverem aumento do número de células mortas e de membranas danificadas, esse tipo de evento foi minimizado quando se utilizou o ACP.
Por outro lado, o impacto que as mudanças na membrana podem ocasionar na função celular deve ser criteriosamente avaliado (Petrunkina et al., 2005). O ACP proporcionou excelente meio para o espermatozoide suíno após sua diluição.

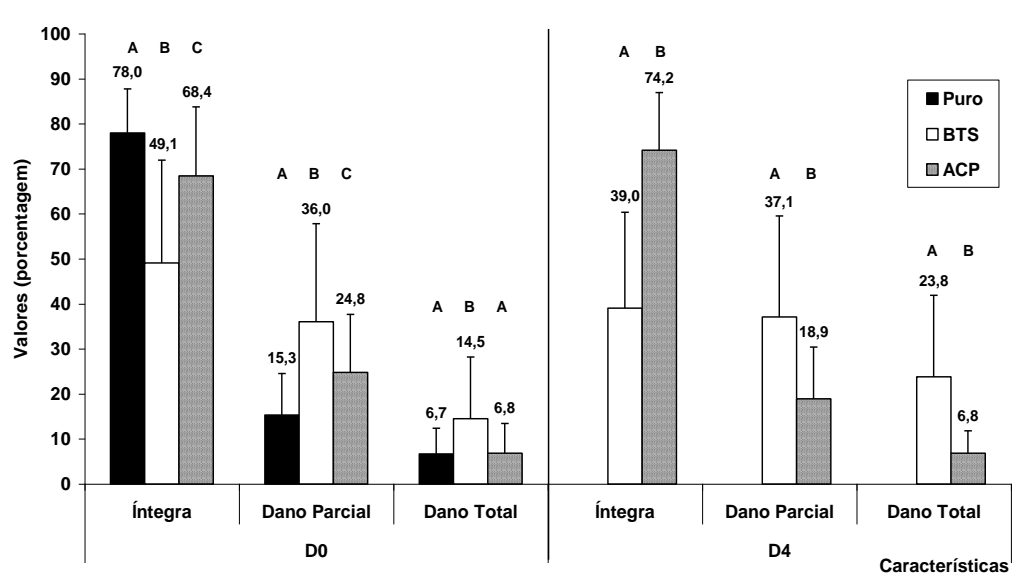

Letras diferentes entre tratamentos, dentro da mesma característica e dia de análise, indicam diferenças significativas $(\mathrm{P}<0,05)$.

Figura 4. Integridade da membrana espermática (\%), do sêmen suíno diluído em BTS e água de coco em pó (ACP), no dia da coleta (D0) e no último dia de conservação (D4), após incubação a $37^{\circ} \mathrm{C}$.

Atualmente, a utilização do sêmen no estado líquido, em programas de inseminação artificial, é a única tecnologia utilizada rotineiramente na suinocultura (Roca et al., 2006), sendo empregada nas criações desde o início de 1930 (Foote, 2002). Contrariamente aos bons resultados obtidos na parte in vitro deste trabalho, com o uso do diluente ACP, os resultados de fertilidade e prolificidade mostraram 10 pontos percentuais e 1,8 leitões a mais no lote de porcas inseminadas com o sêmen diluído no BTS (Tab. 1). Na realidade, o BTS tem se mostrado um excelente diluente, apesar do seu curto período de conservação, com bons resultados, mesmo quando comparado com outros diluentes de longa duração (Haugan et al., 2007).

Na Tab. 2, apresenta-se a distribuição do número de inseminações feitas por reprodutor utilizado no experimento. $\mathrm{O}$ baixo número de ejaculados/reprodutor, devido ao maior peso individual de cada macho, pode ter tido ação decisiva sobre os resultados de fertilidade. Ao menos em parte, o reprodutor 6211 , que só foi utilizado no experimento com o seu ejaculado diluído no ACP e teve o pior resultado de fertilidade, pode explicar o desempenho mais baixo da ACP.

Evidenciou-se o efeito direto do varrão sobre a fertilidade e o tamanho da leitegada (Uzu, 1979), tendo, dessa forma, grande importância nos resultados da inseminação artificial na espécie suína (Paquignon et al., 1988). Um reprodutor de alta qualidade pode assegurar a fecundação de um grande número de fêmeas, e em razão disso, influenciar significativamente a economia da produção segundo sua própria fecundidade (du Mesnil du Buisson et al., 1974). A determinação da qualidade do ejaculado do varrão representa uma fase importante e indispensável da manipulação do sêmen com vistas à sua utilização em programas de inseminação artificial. Ela permite o controle da aptidão reprodutiva do macho e constitui uma vantagem 
da técnica de inseminação artificial em relação à monta natural.

Por outro lado, é conhecido que a taxa de parição também pode ser influenciada por fatores específicos causadores de diferentes falhas reprodutivas (Silveira, 2007), as quais dependem tanto do macho quanto da fêmea, além de outras variáveis externas. Ainda assim, considerando-se como meta a taxa mínima de $90 \%$ de fertilidade, o uso do diluente ACP aproximou-se bastante deste resultado.

Tabela 1. Fertilidade e prolificidade de fêmeas suínas inseminadas com sêmen diluído em BTS e água de coco em pó (ACP)

\begin{tabular}{|c|c|c|c|c|c|c|c|}
\hline \multirow{2}{*}{ Diluente } & \multicolumn{2}{|c|}{ Fertilidade } & \multirow{2}{*}{$\begin{array}{c}\text { Partos } \\
(\%)\end{array}$} & \multicolumn{4}{|c|}{ Prolificidade } \\
\hline & $(+)$ & $(-)$ & & Total & Vivos & Perda $(\%)$ & $M \times F$ \\
\hline $\mathrm{ACP}$ & 26 & 4 & 86,67 & 12 & 10,9 & 9,2 & $6,4 \times 5,3$ \\
\hline BTS & 29 & 1 & 96,67 & 13,6 & 12,7 & 6,6 & $7,1 \times 6,5$ \\
\hline
\end{tabular}

Tabela 2. Distribuição dos resultados individuais de fertilidade obtidos de acordo com o sêmen utilizado em inseminações artificiais e diluído em BTS e água de coco em pó (ACP)

\begin{tabular}{ccccccc}
\hline \multirow{2}{*}{ Diluente } & Macho & $(+)$ & $(-)$ & Total & \% Positivos & Peso/IA $(\%)$ \\
\hline \multirow{3}{*}{ ACP } & 2500 & 8 & 0 & 8 & 100,0 & 26,7 \\
& 2501 & 9 & 0 & 9 & 100,0 & 30,0 \\
& 4154 & 7 & 3 & 10 & 70,0 & 33,3 \\
& 6211 & 2 & 1 & 3 & 66,6 & 10,0 \\
BTS & 2500 & 8 & 1 & 9 & 88,9 & 30,0 \\
& 2501 & 7 & 0 & 7 & & 23,3 \\
& 4154 & 14 & 0 & 14 & 100,0 & 46,7 \\
\hline
\end{tabular}

\section{CONCLUSÕES}

$\mathrm{Na}$ sua quase totalidade, os resultados indicaram que o diluente ACP mostrou-se melhor adaptado às condições necessárias a uma boa conservação do sêmen suíno, sendo sua escolha aconselhável para uso rotineiro em laboratórios de produção de sêmen. Os resultados de fertilidade apontaram o BTS como sendo o melhor, fato este contrário aos resultados in vitro.

\section{AGRADECIMENTOS}

Os autores agradecem ao Conselho Nacional de Desenvolvimento Científico e Tecnológico $(\mathrm{CNPq})$, pelo suporte financeiro; à Granja Suinícola Estiva, por ceder os animais e estrutura; à $\operatorname{Dr}^{\mathrm{a}}$ Cristiane Clemente de Mello da Universidade Estadual do Ceará, pelo fornecimento da ACP- $103^{\circledR}$; e ao Departamento de Reprodução Animal da UNESP, pela acolhida em suas instalações, sem as quais esta pesquisa não poderia ter sido realizada.

\section{REFERÊNCIAS BIBLIOGRÁFICAS}

ARRUDA, R.P.; ANDRADE, A.F.C.; PERES, K.R. et al. Biotécnicas aplicadas à avaliação do potencial de fertilidade do sêmen equino. Rev. Brasil. Reprod. Anim., v.31, p.8-16, 2007.

COSTA, S.H.F.; SANTOS, R.R.; FERREIRA, M.A.L. et al. Preservation of goat pre-antral follicles in saline or coconut water solution. Braz. J. Vet. Anim. Sci., v.39, p.324-330, 2002.

du MESNIL du BUISSON, F.; MILLANVOYE, B.; BARITEAU, F. et al. Facteurs de variation de la production et de la qualité de la semence de verrat: effets saisonniers, héritabilité, corrélation entre variables. Journ. Rech. Porc. France, v.1, p.63-67, 1974.

FIGUEIRÔA, P.T.B.; SALVIANO NETO, P.; OLIVEIRA, R.R. et al. Avaliação da viabilidade do sêmen suíno submetido à refrigeração. Rev. Bras. Reprod. Anim., v.25, p.442-445, 2001. 
FOOTE, R.H. The history of artificial insemination: selected notes and notables. J. Anim. Sci., v.80, suppl. 2, p.235-239, 2002.

HAUGAN, T.; GAUSTAD, A.H.; REKSEN, O. et al. Fertility results of artificial insemination performed with liquid boar semen stored in X-cell vs BTS extender. Reprod. Dom. Anim., v.42, p.9499, 2007.

LEVIS, D.G. Liquid boar semen production: current extender technology and where do we bgo from here. In: INTERNATIONAL CONFERENCE ON BOAR SEMEN PRESERVATION, 4., 2000, Beltsville. Anais ... Beltsville, 2000. p.121-128.

LIMA, F.P.; MURGAS, L.D.S.; MILLER, J. et al. Efeito da concentração espermática e do tempo de incubação na motilidade, vigor e morfologia de espermatozoides suínos. In: XVII CONGRESSO BRASILEIRO DE REPRODUÇÃO ANIMAL, 1, 2007, Curitiba. Anais ... Curitiba, 2007. p.228. (Resumo).

NUNES, J.F.; SALGUEIRO, C.C.M. Utilização da água de coco como diluidor do sêmen de caprinos e ovinos. Rev. Cient. Prod. Anim., v.1, p.17-26, 1999.

PAQUIGNON, M.; BUSSIERE, J.; BARITEAU, J. et al. Effet du dilueur, du taux de dilution et du plasma séminal sur la fertilité des truies après une longue conservation de la semence. J. Rech. Porc. France, v.14, p. 85-90, 1982.

PAQUIGNON, M.; BUSSIERE, J.; BARITEAU, F. Efficacité des techniques de conservation de la semence de verrat. INRA - Prod. Anim., v.1, p.271280, 1988.

PETRUNKINA, A.M.; VOLKER, G.; WEITZE, K.F. et al. Detection of cooling-induced membrane changes in the response of boar sperm to capacitating conditions. Theriogenology, v.63, p.2278-2299, 2005.

ROCA, J.; VAZQUEZ, J.M.; GIL, M.A. et al. Challenges in pig artificial insemination. Reprod. Dom. Anim., v.41, suppl.2, p.43-53, 2006.

RUVALCABA, J.A.G.; CONDE MARTINEZ, P. Por que ocorrem problemas reprodutivos no cachaço, Suínos \& Cia, v.14, p.11-26, 2005

SALGUEIRO, C.C.M; NUNES, J.F.; OLIVEIRA, K.P.L. Utilização de diluentes à base de água de coco in natura e em pó, na inseminação artificial programada de cabras. Rev. Bras. Reprod. Anim., v.26, supl.1, p.156-160, 2002.
SALGUEIRO, C.C.M; NUNES, J.F.; OLIVEIRA, R.V. et al. Inseminação artificial de ovelhas com sêmen diluído em meio à base de água de coco em pó (ACP-102) ou TRIS, resfriado e mantido a $4^{\circ} \mathrm{C}$ por 24 horas. In: CONGRESSO BRASILEIRO DE REPRODUÇÃO ANIMAL, 17., 2007, Curitiba. Anais ... Curitiba, 2007. p.149 (Resumo).

SILVEIRA, P.R.S. Fatores que interferem na taxa de parição em rebanhos suínos. Rev. Bras. Reprod. Anim., v.31, p.32-37, 2007.

SLAWETA, R.; SIKORSKA, J.; STREZEZEK, J. The effect of storing semen at $15-18^{\circ} \mathrm{C}$ for varying lengths of time on morphology and biological value of spermatozoa. Med. Wet., v.37, p.687-690, 1981.

TONIOLLI, R. Pouvoir fecondant des spermatozoïdes de verrat: amèlioration des conditions de conservation. 1996. 91f. Tese (Doutorado) - Université François Rabelais de Tours, Tours, France.

TONIOLLI, R.; MEDEIROS, A.L.M.; FIGUEIREDO, E.L. Morfologia dos espermatozoides de suíno, diluídos no diluidor de Beltsville (BTS) adicionados do ácido 3-indol acético. Rev. Cienc. Anim., v.9, p.61-65, 1999.

UCHOA, D.C.; SATZINGER, S.; AMARAL, M.C. et al. $\mathrm{O}$ uso de diferentes diluidores para inseminação artificial com sêmen canino refrigerado. In: XVII CONGRESSO BRASILEIRO DE REPRODUÇÃO ANIMAL, 17., 2007, Curitiba. Anais ... Curitiba, 2007. p.182 (Resumo).

UZU, G. Influence du verrat sur les principaux paramètres de la productivité du troupeau et sur la durée de gestation. Ann. Zootech., v.28, p.315-323, 1979.

WEITZE, K.F. Timing of artificial inseminaiton in breeding herds. In: CONFERENCE INTERNATIONAL OF BOAR SEMEN PRESERVATION, 3., 1995, Mariense. Anais... Mariense, 1995. p.121.

YAVETZ, H.; HAUSER, R.; YOGEV, L. Advanced methods for evaluation of sperm quality. Andrology., v.27, p.31-35, 1995. 